\title{
Região Norte do Brasil e sua inserção no comércio internacional brasileiro
}

\author{
North Region of Brazil and its inclusion in brazilian international trade
}

\section{Region Nord du Brésil et son inclusion dans le commerce international brésilien}

\author{
Región Norte de Brasil y su inclusión en comercio internacional de brasileño
}

\author{
Mário Sérgio Pedroza Lobão ${ }^{1}$ \\ Alexandre de Souza Corrêa ${ }^{2}$ \\ Mirian Beatriz Schneider ${ }^{3}$
}

Recebido em 03/11/2016; revisado e aprovado em 15/04/2017; aceito em 19/04/2017

DOI: http://dx.doi.org/10.20435/inter.v18i2.1433

\begin{abstract}
Resumo: O objetivo deste artigo é compreender a evolução da inserção da Região Norte do Brasil no comércio exterior brasileiro entre o período de 2006 a 2015. Como procedimentos metodológicos, foram utilizados indicadores de transações comerciais de compra e venda da região com o resto do mundo, como o Índice de Concentração das Exportações (ICX) e Importações (ICM); Índice de Comércio Intrassetorial (ICS); e o número de setores que compõem $90 \%$ do valor total das exportações e importações. Os dados foram coletados no Ministério da Indústria, Comércio Exterior e Serviços (MDIC). Os principais resultados indicam pouco dinamismo regional e de inserção externa, reforçando a vulnerabilidade externa da Região Norte, como também a pouca diversificação de seus produtos, que se concentram no setor de extração mineral e em maior parte no Estado do Pará.
\end{abstract}

Palavras-chave: comércio internacional; inserção econômica; Região Norte.

Abstract: The objective of this article is to understand the evolution of the insertion of the Northern Region of Brazil in Brazilian international trade between the period from 2006 to 2015. As methodological procedures were used indicators of commercial transactions of purchase and sale of the region with the rest of the world, Index of Concentration of Exports (ICX) and Imports (ICM); Intersector Trade Index (ICS); and the number of sectors that make up $90 \%$ of the total value of exports and imports. The data were collected at the Ministry of Industry, Foreign Trade and Services (MIFT). The main results indicate little regional dynamism and external insertion, reinforcing the external vulnerability of the North Region, as well the low diversification of its products, which are concentrated in the mineral extraction sector and in most of the State of Pará.

Key words: international trade; economic integration; North Region.

Résumé: Le but de cet article est de comprendre l'évolution de l'insertion de la région nord du Brésil dans le commerce extérieur du Brésil dans la période allant de 2006 à 2015. Comme les procédures méthodologiques ont été utilisés indicateurs les transactions commerciales d'achat et de vente dans la région avec le reste du monde, Indice de concentration à l'exportation (ICX) et les importations (ICM); Intrasectorielle Trade Index (ICS); et le nombre de secteurs qui représentent $90 \%$ de la valeur totale des exportations et des importations. Les données recueillies au sein du ministère de l'Industrie, du commerce et des services (MDIC). Les principaux résultats indiquent un certain dynamisme d'insertion régionale et internationale, ce qui renforce la vulnérabilité extérieure du Nord, ainsi que la faible diversification de ses produits, qui sont concentrés dans le secteur minier et dans la plupart de l'état de Pará.

Mots-clés: commerce international; l'integration économique; Region Nord.

Resumen: El propósito de este artículo es comprender la evolución de la inserción de la región norte de Brasil en el comercio exterior de Brasil en el período de 2006 a 2015. Como se utilizaron procedimientos metodológicos transacciones comerciales indicadores de compra y venta en la región con el resto del mundo, como Índice de concentración de las exportaciones (ICX) y las importaciones (ICM); Índice de Comercio intrasectorial (ICS); y el número de sectores que conforman el $90 \%$ del valor total de las exportaciones e importaciones. Los datos recogidos en el Ministerio de Industria, Comercio y Servicios (MDIC). Los principales resultados indican algunos dinamismo inserción regional e internacional, reforzando la vulnerabilidad externa de la Norte, así como la baja diversificación de sus productos, que se concentran en el sector de la minería y en la mayor parte del estado de Pará.

Palabras clave: comercio internacional; integración económica; Región Norte.

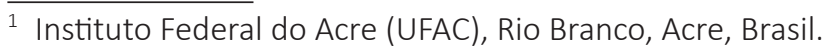

2 Universidade Federal da Grande Dourados (UFGD), Dourados, Mato Grosso do Sul, Brasil.

3 Universidade Estadual do Oeste do Paraná (UNIOESTE), Toledo, Paraná, Brasil.
} 


\section{INTRODUÇÃO}

Países com economias consideradas em desenvolvimento têm como característica adotarem modelos de crescimento econômico voltados para o sucesso na inserção externa, por meio de suas capacidades e estruturas produtivas. Os incentivos às exportações se tornam essenciais para uma maior dinâmica de expansão da produção doméstica, evitando uma produção interna pouca diversificada. Nesse sentido, deve-se atentar aos níveis de inserção externa que as regiões propiciam ao país, no intuito de elevar a produção e diversificar seus produtos para o consumo externo.

Com o intenso processo de abertura econômica verificada no início da década de 1990 no Brasil, acirrou-se a competitividade dos produtos nacionais no mercado externo, por meio de pesquisa em novas tecnologias e do estímulo a produtividade, que se estendem conjuntamente com o Plano Real. Esse cenário revelou uma industrialização brasileira com baixo grau de dinamismo na comercialização de produtos manufaturados, característico de políticas industriais protecionistas adotadas nas décadas passadas.

A partir dessas constatações e do entendimento de que o Brasil apresenta uma relação diferenciada dentro das suas macrorregiões com o setor externo, seja devido às especificidades econômicas regionais ou mesmo decorrente da sua extensão territorial, passa-se aqui a buscar compreender como a região Norte do Brasil tem se comportado e contribuído, no decorrer dos os últimos 10 anos (2006-2015), no comércio exterior brasileiro. O lapso temporal escolhido deve-se tanto pela disponibilidade de dados como por comportar fatos econômicos importantes, como é o caso da crise de 2008.

Ademais, justifica-se a pesquisa esclarecendo que o estudo da evolução das relações comerciais externas da Região Norte permite identificar seu comportamento comercial externo e sua contribuição produtiva para o país, apontando elementos que definem a estrutura produtiva da Região e seu grau de inserção externa.

A caracterização de como a Região Norte têm se comportado entre os anos de 2006 e 2015, na sua dinâmica no cenário internacional via comércio de importações e exportações, refletem, na base produtiva da região, quanto em sua especialização em determinado seguimentos produtivos. Para melhor compreensão dessas questões, com base nos dados disponíveis pelo Ministério da Indústria, Comércio Exterior e Serviços (MDIC), analisou-se no trabalho a evolução de alguns indicadores que contribuíssem para compreender o grau de concentração de exportações e importações, como também o índice de comércio intrassetorial na Região Norte.

Este trabalho se subdivide em mais quatro seções, além desta introdução. Na segunda seção, apresenta-se o referencial teórico da pesquisa; posteriormente, os procedimentos metodológicos; na quarta seção, são discutidos e apresentados os resultados; por fim, as conclusões encerram o estudo.

\section{REFERENCIAL TEÓRICO}

De acordo com a literatura econômica, as teorias que procuram explicar o comércio internacional estão divididas em duas vertentes, a primeira é a teoria clássica de comércio exterior que ilustra os fatores de produção de um país quanto a sua especialização na produção de bens ou serviços em que possui maior produtividade. Sobre uma visão de modelo mais empirista; a segunda vertente esboça um papel sobre as determinantes nas Vantagens Competitivas entre

INTERAÇÕES, Campo Grande, MS, v. 18, n. 2, p. 87-101, abr./jun. 2017. 
os países, analisando a dinâmica dos setores empresariais e industriais que se destacam em âmbito internacional.

Até a segunda metade do século XVIII, o estudo do comércio internacional se baseava no mercantilismo, em que as forças econômicas e políticas de uma nação eram medidas pela sua riqueza em metais preciosos, preconizando a comercialização e o incentivo às exportações para obtenção de saldos positivos na balança comercial.

Adam Smith (1996) destacou a pouca importância do comércio exterior para países que não dispusessem de minas de exploração próprias para aquisição de metais preciosos. Logo, o contexto produtivo de uma nação se tornaria algo fundamental para o livre comércio de trocas entre nações. Para tanto, o país deveria produzir determinado bem que possuísse vantagem absoluta em termos de melhor uso de insumos de produção. Ou seja, produzir determinado produto que possuísse maior produtividade e comercializar seu excedente com outra nação em que houvesse maior produtividade de outro produto.

As vantagens absolutas preconizavam que o comércio entre nações somente aconteceria se ambas as nações tivessem vantagens na produção de determinados produtos, para que, assim, pudessem ocorrer as trocas de excedentes. David Ricardo (1996) desenvolveu a Teoria das Vantagens Comparativas, como um avanço da proposta das Vantagens Absolutas, pois mesmo possuindo desvantagens na produção de determinado produto, uma nação ainda poderia comercializá-lo.

A Teoria das Vantagens Comparativas pode ser compreendida por meio da análise do custo oportunidade que dois países terão ao deixar de produzir um bem em detrimento de focar na produção de outro bem. Nesse modelo, a produtividade do fator trabalho para distintos bens são relativamente provenientes das vantagens comparativas. Com o aumento da produção doméstica de um país que se especializa em um determinado bem, a produção que não fosse vendida no mercado interno deveria ser vendida ao mercado externo, outros produtos seriam adquiridos a um custo menor do que produzido internamente no país, mantendo um comércio benéfico entre os países (COUTINHO et al., 2005).

Schneider e Araújo (2014) e Coutinho et al. (2005) destacam que, apesar das restrições que a Teoria das Vantagens Comparativas possui, como considerar a competição perfeita entre os países, os estudos empíricos confirmam o modelo básico de Ricardo, em que países exportam bens de maior produtividade e importam bens de menor produtividade. Esses estudos foram ampliados e quantificados por autores neoclássicos, assumindo algumas premissas das Teorias das Vantagens Absolutas e Comparativas, como o Teorema da Equalização dos preços dos fatores (Teorema de Heckscher Ohlin), Teorema de Stolper-Samuelson e o Teorema de Rybczynskhe.

O Teorema de Heckscher Ohlin enfatiza as diferenças de recursos como a única fonte de comércio, a vantagem comparativa é influenciada por recursos relativamente abundantes e intensivos, ou seja, um país exportará bens intensivos nos fatores cuja oferta é abundante (baixo custo) e importará aqueles que empregam intensivamente seu fator escasso (elevado custo). Isto implica que, quando um país local comercializa seu bem com um país estrangeiro, os preços relativos convergem, o comércio proporcionará uma redução ou eliminação de diferenças dos preços de fatores entre os países (KRUGMAN; OBSTEFELD, 2005).

O Teorema de Stolper-Samuelson contextualiza que o crescimento no preço relativo de um bem aumenta os retornos nominais e reais do fator usado intensivamente na produção do bem, enquanto o retorno nominal e real do fator do outro bem diminui. Krugman e Obstefeld 
(2005) destacam que o Teorema de Rybczynski diferencia de Stolper-Samuelson ao enfatizar que, se o preço de um bem for fixo, um aumento no uso de um fator de produção para determinado bem aumenta a oferta desse bem, ocasionando uma queda na produção do outro bem para quaisquer preços.

Em síntese, as teorias clássicas e neoclássicas que estudam o uso dos fatores de produção fundamentado na vantagem comparativa, apresentaram falhas quando inseridas na realidade dos padrões do comércio internacional, pois os pressupostos dos modelos tendem a apresentar um padrão estático.

Novos modelos surgiram para complementar as teorias neoclássicas do comércio internacional, inserindo variáveis como os mercados de concorrência imperfeita, o processo de inovação e as economias de escala. Esses modelos consideraram principalmente, o comportamento dos consumidores entre países. Nessa nova abordagem, cabe destacar dois modelos, o modelo de Linder (1961), que preconizou o lado da demanda dos consumidores, determinada pela renda e preferências dos consumidores que influenciam no comércio internacional de acordo com o grau de semelhança entre países, e o modelo da Teoria do Ciclo Produto de Raymond Vernon (1972), que destacou o comércio internacional e o desenvolvimento tecnológico, em que os produtos mais avançados em termos tecnológicos têm vantagens comparativas nos países com economias desenvolvidas, somente com o passar do tempo essa vantagem comparativa é dissolvida nos países com economias em desenvolvimento (ALVARENGA, 2015).

Para Krugman e Obstefeld (2005), esses modelos de Linder e Vernon se enquadram em teorias de comércio de bens industrializados, que grandes volumes de trocas condicionaram a uma liberalização do comércio, contudo não são esclarecidos os padrões de trocas e de produtos. Para Coutinho et al. (2005), é a partir de Porter (1989) que se consegue compreender o papel das multinacionais nos aspectos de inovação, demanda e vantagens concorrenciais.

Com o avanço da globalização nas últimas três décadas, as explicações das teorias convencionais clássicas e neoclássicas tornaram-se cada vez mais complexas para compreender uma acelerada intensidade nos aumentos dos fluxos de capitais e na reestruturação produtiva de recursos tecnológicos das telecomunicações e informática. Lacerda (2003, p. 12) salienta que esses aspectos não só reduziram os custos de transações das empresas, como também diminuíram o ciclo de vida dos produtos e suas tecnologias, propiciando uma corrida pela inovação de produtos e serviços. "O acirramento da concorrência internacional diante deste novo cenário tem suscitado, em muitos casos, um movimento de protecionismo e formação de blocos de mercados comuns, que contrariam as generalizações atribuídas à globalização".

Essas mudanças na competitividade internacional são trabalhadas por Porter (1989) como um modelo dinâmico, em que o grau de produtividade no uso de recursos nacionais define quão próspera economicamente a nação será. É importante destacar a preocupação do autor com a economia doméstica, pois a vantagem competitiva surge somente nas diferenças dos valores nacionais, históricos, culturais, estruturais e institucionais. Essas diferenças culminam de que uma nação não pode ser capaz de ser competitiva em todos os setores de negócios ao mesmo tempo, mas sim, em setores específicos em que ela tende a ser mais progressista e dinâmica.

Coutinho et al. (2005) salientam o respaldo da teoria econômica já consagrada nos argumentos de Porter, pois a produtividade se assemelha à Teoria das Vantagens Comparativas de David Ricardo, e o aspecto da inovação, considerada por Porter como principal responsável pelo progresso dinâmico da economia, baseia-se no argumento schumpeteriano. Assim, a proposta 
do estudo de Porter sobre a vantagem competitiva de uma nação está no entendimento das bases em que surgem tais vantagens e como os governos e empresas podem adotar políticas que diferenciem competitivamente e de forma positiva sua nação.

Em economias de países em desenvolvimento, é característico um modelo de crescimento econômico voltado para obtenção de saldos na balança comercial como incentivo a maiores volumes de produção doméstica. Esses aspectos recorrem a um possível e melhor bem-estar econômico e social no país.

É importante salientar o que Medeiros e Serrano (2001, p. 107) evidenciaram nas leituras de Prebisch: "as exportações podem ser mais ou menos importante para expansão da economia - de acordo com uma série de características estruturais de cada país - [...]". Contudo os autores destacam o papel primordial das exportações sobre o relaxamento das políticas de restrição e financiamento externo para aqueles países que não obtêm o controle da oferta de moeda de circulação nacional.

Baumann (2010) sintetiza o parâmetro internacional do Brasil em conjunto com as políticas de industrialização protecionistas na década de 1950 e 1960, e essas políticas contaram com fortes aportes de investimentos externos. De forma semelhante ocorrera em 1990, com a intensificação da abertura comercial e da promoção de comércio preferencial em base regional.

Historicamente no Brasil, assim como em outros países da América Latina, o comércio e o crescimento se despontaram de forma desigual quando comparado com países de economias desenvolvidas. Para Sarquis (2011), as crises externas, como o choque do petróleo, déficits no Balanço de Pagamentos e o reconhecimento tardio do protecionismo que as políticas de Substituição de Importações promoveram com as indústrias nacionais, prejudicaram que um novo modelo de inserção econômica internacional se desenvolvesse de forma prudente.

Para o autor, a partir da década de 1990, têm-se, no Brasil, políticas de liberalização comercial drásticas, de caráter unilateral e limitado ao grau de abertura das economias. As reformas políticas e econômicas em prol da estabilidade e abertura competitiva ignoraram os problemas estruturais voltados para a produtividade e inovação, diferentemente dos países centrais, como Alemanha, França, Japão e Coreia, que obtiveram elevados e diferenciados graus de sucesso no pós-Guerra.

Nesse contexto, as políticas cambiais de apreciação da moeda nacional para manter a estabilização econômica contemplada com o Plano Real a partir de 1994 culminaram em elevadas taxas de crescimento das importações, enquanto as exportações cresceram a pequenas taxas durante a década de 1990. Em decorrência dessas políticas, em 1995 a balança comercial já apresentava saldos negativos, deixando o país com alta vulnerabilidade externa. Silva (2004, p. 07) complementa que "o processo de desenvolvimento do país passou a depender de sua capacidade de competir interna e externamente com os bens produzidos nos demais países inseridos no comércio internacional".

A década de 2000 já apresentou um processo de liberalização econômica e financeira menos impactante do que a década de 1990. A participação das exportações brasileiras industriais declinou em relação a produtos manufaturados devido à baixa produtividade industrial e pouca maturação da boa parte da indústria de projetar-se globalmente. Com o setor industrial pouco dinâmico, percebe-se a especialização em determinadas commodities do setor agrícola como uma condição grave na capacidade de diversificar e expandir as exportações (SARQUIS, 2011).

Em estudo realizado por Gordon e Gromkow (2011) sobre as características estruturais do Brasil na inserção externa, os autores identificaram três resultados na década de 2000: i) crescente 
concentração em setores intensivos em recursos naturais, com alimentos, bebidas, papel e celulose, refino de petróleo e metalurgia básica; ii) crescente participação das importações por setores de cunho altamente tecnológicos; e iii) setores de uso de mão de obra intensiva (têxtil, couro e calçados) perderam espaço nas exportações e ganharam nas importações.

Assim, com base nos autores, o país mostrou-se ao longo da década de 2000 uma especialização em produtos de menor valor agregado e de baixo conhecimento técnico e uma maior dependência externa de produtos mais complexos tecnologicamente. Esses aspectos tendem a inibir o processo de desenvolvimento econômico, uma vez que essa dependência apresenta um processo de menor difusão de conhecimento e de uma especialização regressiva e menos competitiva em âmbito internacional.

\section{METODOLOGIA}

Visando analisar a inserção internacional da Região Norte no comércio exterior brasileiro, tomam-se como período de análise os últimos 10 anos, portanto, dos anos 2006 a 2015. Lacerda (2011) explica que, nos últimos 10 anos, o Brasil tornou-se mais respeitado no mercado internacional, dependendo menos de recursos externos e, assim, conseguindo uma sustentação própria no comércio exterior. Nesse sentido, entende-se que esses resultados tenham se disseminado por toda sua extensão territorial, inclusive na Região Norte do Brasil.

Nesse contexto, trabalha-se com as peculiaridades do comércio exterior da Região Norte brasileira, observando o saldo da balança comercial e as exportações e importações nacionais por fator agregado. Não obstante, avaliam-se as exportações e importações quanto aos aspectos das contas nacionais, bem como os principais setores que se destacam na pauta de exportação da região. Para análise regional, são abordados ainda instrumentos que permitem delinear, de forma mais detida, as características de transações comerciais de compra e venda da região com o resto do mundo. Assim, optou-se por calcular os indicadores: Índice de Concentração das Exportações (ICX) e Importações (ICM); Índice de Comércio Intrassetorial (ICS); e o número de setores que compõem $90 \%$ do valor total das exportações e importações.

Para medir o nível de concentração, tanto das exportações quanto das importações por setor, foi utilizado o coeficiente de Gini-Hirchman. De acordo com Silva e Montalván (2008), a partir do cálculo do coeficiente de Gini-Hircchman, se as exportações (importações) apresentarem um alto grau de concentração em uma pequena quantidade de produtos, indica que a economia nacional se sujeita às flutuações da demanda internacional, o que impacta diretamente na balança comercial do país, aqui se estabelece essa relação para o setor. O coeficiente é dado conforme Equação 01:

$$
I C=100 . \sqrt{\sum_{i}\left(\frac{X_{i}}{X}\right)^{2}}
$$

Em que $X_{i}$ representa o total de exportação (importação) do setor $i, X$ trata do total das exportações (importações) da região. Cabe ressaltar que esse indicador varia de zero a 100, na medida em que quanto mais próximo de 100, mais concentrada é a pauta de exportação (importação) no setor analisado; raciocínio inverso é feito para valores próximos de zero.

INTERAÇÕES, Campo Grande, MS, v. 18, n. 2, p. 87-101, abr./jun. 2017. 
Para a análise do comércio intrassetorial da Região Norte, utilizou-se o coeficiente de Grubel e Lloyde (1975 apud GREENAWAY; MILNER, 2003). Esse indicador permite verificar a intensidade das transações de trocas de produtos do mesmo setor entre a região e o resto do mundo. É dado pela Expressão 02:

$$
I S=1-\frac{1 X_{i}-M_{i} 1}{\left(X_{i}-M_{i}\right)}
$$

Em que $X_{i}$ refere-se às exportações do setor $i$ e $M_{i}$ refere-se às importações do setor $i$. 0 coeficiente possui intervalo de zero a 100. Segundo Melo (2013), quanto mais próximo de zero for o resultado do indicador, maior será o relacionamento de trocas decorrentes de setores tradicionais de vantagens comparativas; já quando o indicador se aproximar de 100, tem-se um comércio intrassetorial elevado, ou seja, as trocas não são explicadas pelas vantagens comparativas.

O conjunto de dados utilizados na pesquisa foram todos extraídos da plataforma on-line do Ministério da Indústria, Comércio Exterior e Serviços (MDIC) (BRASIL, 2016), a partir das estatísticas de comércio exterior, disponível em: <http://www.mdic.gov.br/comercio-exterior/ estatisticas-de-comercio-exterior>. Seguiu-se a Nomenclatura Comum do Mercosul (NCM) para as denominações dos setores estudados, conforme adotada pela Secretaria de Comércio Exterior do MDIC.

\section{REGIÃO NORTE DO BRASIL E SUA INSERÇÃO NO COMÉRCIO EXTERIOR BRASILEIRO}

A Região Norte, no ano de 2015, apresentou uma participação de 6,91\% no total das exportações do Brasil, com valor bruto de US\$13.206.860.584. Dentre as outras regiões brasileiras, foi a que apresentou o menor percentual, no entanto, observando os dados disponibilizados pelo MDIC (BRASIL, 2016), as importações representaram um total de $6,20 \%$ do total nacional, com valor bruto de US\$10.632.025.411, somente a Região Centro Oeste apresentou resultado inferior, com valor de $5,43 \%$. Com isso, no saldo total da balança comercial brasileira, o Norte brasileiro representou $13,08 \%$, ficando atrás somente da Região Sul $(24,34 \%)$ e Centro-Oeste $(74,41 \%)$. As regiões Nordeste e Sudeste apresentaram saldo negativo na composição geral.

A Tabela 1 mostra detalhadamente o saldo da balança comercial da Região Norte no período de 2006 a 2015. Percebe-se que as exportações da região crescem de 2006 a 2008, porém, em 2009 , tem um recuo de mais de $22 \%$, seguindo a tendência nacional e decorrente da crise de 2008, reduzindo a demanda internacional, bem como uma queda nos preços das commodities. Não obstante, os anos de 2010 e 2011 representaram um ganho significativo para a inserção da Região Norte no cenário internacional, inclusive, com marca histórica em 2011 com níveis recordes de exportação, representando o maior saldo na balança comercial dos anos analisados.

A Associação do Comércio Exterior do Brasil (AEB, 2012) explica que o ano de 2011 foi marcado por níveis recordes das cotações dos preços das commodities, isto muito "[...] graças à forte demanda da China e ao favorável cenário econômico internacional [...]" (AEB, 2012, p. 05). Sendo assim, esses efeitos foram sentidos e expressados na balança comercial do Brasil, assim como difundido por todas as regiões nacionais, não diferente com a Região Norte, que concentra na sua maioria a exportação de produtos básicos. 
Tabela 1 - Saldo da balança comercial da Região Norte do Brasil entre 2006 e 2015, em US\$ 1000

\begin{tabular}{cccccc}
\hline \multirow{2}{*}{ ANO } & \multicolumn{2}{c}{ EXPORTAÇÕES } & \multicolumn{2}{c}{ IMPORTAÇÕES } & SALDO \\
\cline { 2 - 6 } & VALOR & VAR\% & VALOR & VAR\% & EXP - IMP \\
\hline 2006 & 8.918 .197 .416 & 20,22 & 6.996 .407 .046 & 23,23 & 1.921 .790 .370 \\
2007 & 9.808 .846 .499 & 9,99 & 7.675 .714 .672 & 9,71 & 2.133 .131 .827 \\
2008 & 13.059 .898 .322 & 33,14 & 11.379 .728 .461 & 48,26 & 1.680 .169 .861 \\
2009 & 10.111 .820 .867 & $-22,57$ & 8.079 .109 .539 & $-29,00$ & 2.032 .711 .328 \\
2010 & 15.110 .941 .715 & 49,44 & 12.737 .717 .289 & 57,66 & 2.373 .224 .426 \\
2011 & 20.861 .452 .592 & 38,06 & 14.725 .848 .032 & 15,61 & 6.135 .604 .560 \\
2012 & 17.692 .850 .851 & $-15,19$ & 15.701 .577 .681 & 6,63 & 1.991 .273 .170 \\
2013 & 19.088 .625 .445 & 7,89 & 16.143 .743 .674 & 2,82 & 2.944 .881 .771 \\
2014 & 17.597 .021 .792 & $-7,81$ & 14.900 .293 .584 & $-7,70$ & 2.696 .728 .208 \\
2015 & 13.206 .860 .584 & $-24,95$ & 10.632 .025 .411 & $-28,65$ & 2.574 .835 .173 \\
\hline
\end{tabular}

Fonte: Elaborado pelos autores a partir da SECEX/MDIC (BRASIL, 2016).

O saldo da balança comercial da Região Norte tem apresentado um comportamento equilibrado ao longo dos anos de 2006 a 2015, conforme Gráfico 1. Com exceção do Norte e Centro-Oeste, que apresentaram sempre superávit na balança comercial nos últimos 10 anos, as demais regiões brasileiras apresentaram grandes oscilações, principalmente, acumulando déficits, o que explica as grandes variações na curva do saldo da balança comercial brasileira de 2006 a 2015, atingindo um saldo negativo no ano de 2014, decorrente dos déficits das Regiões Nordeste, Sul e Sudeste, que totalizaram US\$-25.336.478.077.

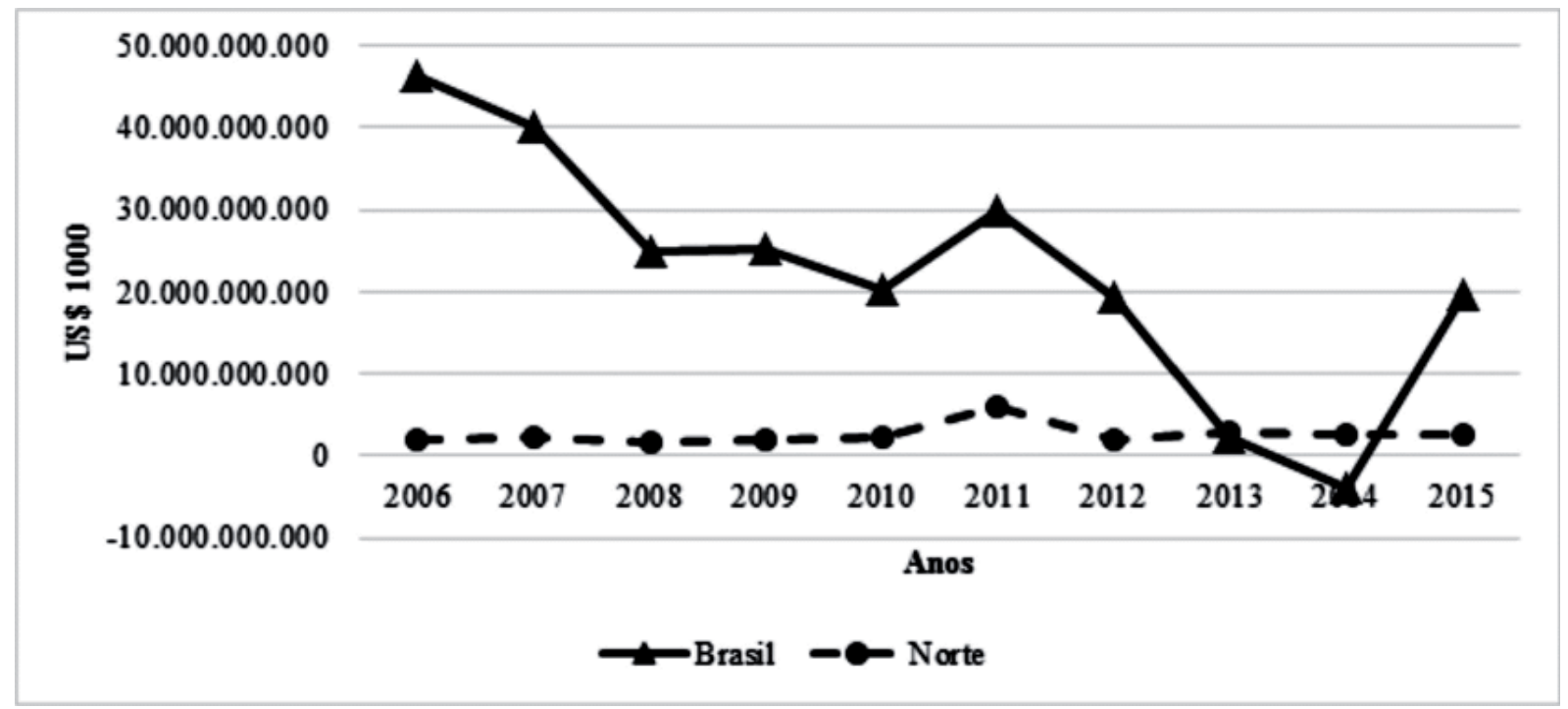

Gráfico 1 - Saldo da balança comercial do Brasil e Região Norte (2006 - 2015) Fonte: Elaborado pelos autores a partir da SECEX/MDIC (BRASIL, 2016).

A tendência nacional do aumento de exportações de produtos básicos em detrimento daqueles com maior valor agregado é seguida pela Região Norte, observado pela Tabela 2. De 2006 a 2015, as exportações básicas representaram uma variação de cerca de 70\%, saindo de uma participação de 40,79\% para 69,27\% do total por fator agregado, respectivamente. Já os produtos industrializados, no mesmo período, tiveram uma redução de mais de $48 \%$, caindo de uma participação de 59,21\% em 2006 para 30,73\% em 2015. 
Pela ótica das importações, é perceptível que o Norte brasileiro concentrou mais de 95\% de transações comerciais de produtos industrializados, ao longo dos últimos 10 anos. Verifica-se que esta tendência tende a perdurar, haja vista ocorrer variações muito pequenas do total da participação dos produtos industrializados nas importações. Essa evidência é preocupante, pois as relações e os termos de troca da região estão se deteriorando, uma vez que se verifica um grau de importação altamente de produtos industrializados em contraste com a exportação de um volume cada vez maior de mercadorias de fator agregado básico.

Tabela 2 - Participação das Exportações e Importações por Fator Agregado na Região Norte entre os anos de 2006-2015 (em \%)

\begin{tabular}{ccccc|cccc}
\hline & \multicolumn{4}{c}{ EXPORTAÇÕES } & \multicolumn{4}{c}{ IMPORTAÇÕES } \\
\cline { 2 - 9 } ANO & Básicos & $\begin{array}{c}\text { Semimanufaturados } \\
\text { (A) }\end{array}$ & $\begin{array}{c}\text { Manufaturados } \\
\text { (B) }\end{array}$ & $\begin{array}{c}\text { Industrializados } \\
\text { (A+B) }\end{array}$ & Básicos & $\begin{array}{c}\text { Semimanufaturados } \\
\text { (A) }\end{array}$ & $\begin{array}{c}\text { Manufaturados } \\
\text { (B) }\end{array}$ & $\begin{array}{c}\text { Industrializados } \\
\text { (A+B) }\end{array}$ \\
\hline 2006 & 40,79 & 26,21 & 33,00 & 59,21 & 0,79 & 3,50 & 95,71 & 99,21 \\
2007 & 45,49 & 25,58 & 28,93 & 54,51 & 1,35 & 4,34 & 94,31 & 98,65 \\
2008 & 54,79 & 20,92 & 24,29 & 45,21 & 2,06 & 3,79 & 94,15 & 97,94 \\
2009 & 61,45 & 14,61 & 23,94 & 38,55 & 1,52 & 3,84 & 94,64 & 98,48 \\
2010 & 68,86 & 12,26 & 18,88 & 31,14 & 1,82 & 3,67 & 94,51 & 98,18 \\
2011 & 75,99 & 10,66 & 13,35 & 24,01 & 1,96 & 4,13 & 93,91 & 98,04 \\
2012 & 74,99 & 10,28 & 14,72 & 25,01 & 1,24 & 3,38 & 95,39 & 98,76 \\
2013 & 79,45 & 8,08 & 12,47 & 20,55 & 1,37 & 2,58 & 96,04 & 98,63 \\
2014 & 74,44 & 10,25 & 15,30 & 25,56 & 1,30 & 2,74 & 95,96 & 98,70 \\
2015 & 69,27 & 11,21 & 19,52 & 30,73 & 3,10 & 3,10 & 93,80 & 96,90 \\
\hline
\end{tabular}

Fonte: Elaboração própria a partir de dados da SECEX/MDIC (BRASIL, 2016).

Vale ressaltar que, dentro do contexto da Região Norte, a Zona Franca de Manaus representa uma política de desenvolvimento regional que permite a importação de mercadorias com isenção ou redução de impostos, inclusive, compreende uma área de livre comércio que abrange os Estados do Acre, Amazonas, Rondônia e Roraima, bem como as cidades de Macapá e Santana no Amapá (SUPERINTENDÊNCIA DA ZONA FRANCA DE MANAUS [SUFRAMA], 2016). A Zona Franca de Manaus foi criada com o intuito de fortalecer um centro industrial, comercial e agropecuário, dentro do contexto e interior amazônico (BRASIL, 1967). Fica no Estado do Amazonas o grande polo industrial beneficiado com os incentivos fiscais especiais, localizado na cidade de Manaus, o que tem explicado o Amazonas ser o único Estado da Região Norte a apresentar saldo negativo no balanço de pagamentos. Isto também justifica o alto grau de importação de produtos manufaturados, uma vez que a Zona Franca de Manaus importa muitos componentes eletrônicos intermediários para a industrialização, para posterior montagem em produtos finais como eletroeletrônicos, eletrodomésticos, dentre outros (SUFRAMA, 2016).

Quanto aos setores das contas nacionais da Região em estudo, mediante Tabela 03, é notório que o comércio exportador é predominantemente de bens intermediários com 84,77\% do total em 2015, com destaque para os insumos industriais e alimentos e bebidas destinados à indústria, mas cabe alertar que os insumos industriais tiveram uma queda de mais de $40 \%$ de 2012 a 2015. A Zona Franca de Manaus aqui também representa um grande papel, pois, além de incentivos fiscais especiais para o setor de importação, estes são estendidos às exportações. Bens de consumo (14,23\%) é o segundo setor das contas nacionais mais representativo da pauta 
de exportação, principalmente, os bens de consumo semiduráveis ou não duráveis, seguido com uma pequena parcela de $0,65 \%$ do setor de bens de capital.

As importações por setores das contas nacionais na Região Norte têm na sua composição os bens de capital liderando com 58,80\% em 2015 do total, sendo os bens de capital com exceção daqueles destinados ao transporte industrial predominante. O setor de bens intermediários aparece como o segundo mais importante, acompanhado pelos bens de consumo. Diante disso, verifica-se que a Região compensa claramente sua falta de produção de bens de capital por meio das importações. O setor de combustíveis e lubrificantes não possui representatividade nem nas exportações, nem nas importações regionais.

Tabela 3 - Exportações e importações da Região Norte de acordo com os setores das contas nacionais entre 2012-2015 (em \%)

\begin{tabular}{lccccc|ccc}
\hline \multirow{2}{*}{\multicolumn{1}{c}{ SETORES DAS CONTAS NACIONAIS }} & \multicolumn{3}{c|}{ Exportação } & \multicolumn{5}{c}{ Importação } \\
\cline { 2 - 9 } & 2015 & 2014 & 2013 & 2012 & 2015 & 2014 & 2013 & 2012 \\
\hline BENS DE CONSUMO (BC) & 14,23 & 11,39 & 10,12 & 8,71 & 5,44 & 4,85 & 5,10 & 5,82 \\
Bens de consumo duráveis & 1,19 & 1,29 & 1,25 & 1,21 & 1,05 & 1,35 & 1,53 & 2,03 \\
Bens de consumo semiduráveis e não duráveis & 13,04 & 10,10 & 8,87 & 7,50 & 4,39 & 3,50 & 3,58 & 3,79 \\
COMBUSTíVEIS E LUBRIFICANTES & 0,00 & 0,08 & 0,03 & 0,06 & 2,45 & 3,14 & 3,38 & 5,34 \\
BENS INTERMEDIÁRIOS (BI) & 84,77 & 87,26 & 88,24 & 89,32 & 33,32 & 30,23 & 30,12 & 29,40 \\
Peças e acessórios para bens de capital & 0,10 & 0,10 & 0,15 & 0,13 & 7,37 & 6,51 & 6,83 & 7,15 \\
Insumos industriais & 39,33 & 40,62 & 79,39 & 81,27 & 25,01 & 22,92 & 22,41 & 21,58 \\
Alimentos e bebidas destinados à indústria & 21,62 & 19,78 & 8,70 & 7,92 & 0,94 & 0,79 & 0,88 & 0,67 \\
Peças para equipamentos de transporte & 0,00 & 0,00 & 0,00 & --- & 0,00 & 0,00 & 0,00 & 0,00 \\
BENS DE CAPITAL (BK) & 0,65 & 0,74 & 1,15 & 1,37 & 58,80 & 61,78 & 61,39 & 59,44 \\
Equipamentos de transporte industrial & 0,04 & 0,21 & 0,00 & 0,00 & 1,05 & 1,15 & 1,76 & 1,06 \\
Bens de capital (exceto equip. de transp. ind.) & 0,61 & 0,53 & 1,15 & 1,37 & 57,74 & 60,63 & 59,63 & 58,38 \\
DEMAIS OPERAÇÕES & 0,34 & 0,54 & 0,45 & 0,54 & --- & -- & --- & 0,00 \\
TOTAL & 100 & 100 & 100 & 100,00 & 100 & 100 & 100 & 100 \\
\hline
\end{tabular}

Fonte: Elaborado pelos autores a partir da SECEX/MDIC (BRASIL, 2016).

Dentre os principais setores exportadores classificados segundo a Nomenclatura Comum do Mercosul (NCM), dado pela Tabela 4, encontra-se o de minérios, escórias e cinzas (26), este concentrou no ano de 2014 mais de $50 \%$ de toda a pauta regional de exportação sofrendo uma redução de quase 10\% em 2015, no entanto, mesmo com a queda o setor, liderou as transações comerciais com uma diferença de mais de $33,65 \%$ do segundo colocado, o setor de produtos químicos e inorgânicos; compostos inorgânicos ou orgânicos (28). No decorrer desses dois últimos anos, com exceção do setor de ferro fundido, ferro e aço (72), todos os outros, demonstrados na Tabela 4, ganharam participação na pauta de exportação da Região Norte.

A alta concentração das exportações no setor de minérios, escórias e cinzas (26) é devido a ter a Região uma produção de minérios elevada comparando-se com os demais produtos transacionados pela região com o resto do mundo, principalmente, com uma produção em larga escala no Estado do Pará. Sobre isto, os autores Villa Verde, Alamino e Fernandes (2014) esclarecem que o Estado do Pará tem a extração mineral como base de sua economia, com evidência para o ferro, bauxita, manganês, calcário, ouro e estanho. Ainda segundo os autores, são os municípios de Parauapebas e Canaã dos Carajás que concentram a maior produção dos minérios, no entanto 
Marabá e Barbacena sobressaem-se devido a possuírem indústrias de beneficiamento mineral. O mais impressionante é que, no ano de 2015, o Estado do Pará concentrou 99,66\% de toda a produção do setor, conforme os dados do MDIC (BRASIL, 2016).

Tabela 4 - Participação dos principais setores exportadores da Região Norte de 2015 (20142015) (em\%)

\begin{tabular}{clcc}
\hline NCM & \multicolumn{1}{c}{ SETORES } & PART. 2015 & PART. 2014 \\
\hline 26 & Minérios, escórias e cinzas & 45,87 & 54,21 \\
28 & Produtos químicos e inorgânicos; compostos inorgânicos ou orgânicos & 12,22 & 8,75 \\
12 & Sementes e frutos oleaginosos; grãos, semestres e frutos diversos & 9,45 & 7,41 \\
02 & Carnes e miudezas, comestíveis & 6,97 & 5,79 \\
76 & Alumínio e suas obras & 4,19 & 3,70 \\
44 & Madeira, carvão vegetal e obras de madeiras & 2,80 & 2,38 \\
72 & Ferro fundido, ferro e aço & 2,52 & 3,05 \\
21 & Preparações alimentícias diversas & 2,10 & 1,46 \\
09 & Café, chá, mate e especiarias & 1,74 & 1,17 \\
25 & Sal; enxofre; terras e pedras; gesso, cal e cimento & 1,46 & 1,19 \\
71 & Pérolas naturais ou cultivadas, pedras preciosas ou semipreciosas & 1,42 & 1,29 \\
\hline
\end{tabular}

Fonte: Elaborado pelos autores a partir da SECEX/MDIC (BRASIL, 2016).

O índice de concentração das exportações por setores (ICX) apresentou uma redução de 2014 para 2015 no valor de 6,77\%, conforme Tabela 5, o que representa uma pequena diversificação na pauta de exportação de um ano para o outro, porém ainda com um valor altamente elevado, uma vez que, em 2015, a ICX mostrou-se com quase $47 \%$ de concentração das exportações. Destaca-se que esse resultado é reflexo daquele observado anteriormente, quanto aos setores, como foi o caso do de minérios, escórias e cinzas. Nesse sentido, enfatiza-se a necessidade de diversificação da comercialização regional com o resto do mundo, pois uma pauta muito concentrada representa um perigo eminente, haja vista que, se o setor de concentração sofrer algum impacto de queda no setor externo, o resultado será catastrófico para a economia da região, como é o caso dos minérios.

A concentração das importações (ICM), por sua vez, segue a mesma tendência das exportações, entretanto, com um nível maior de concentração, com quase 59\% no ano de 2015. O setor que mais contribui para essa concentração é o de máquinas, aparelhos, materiais elétricos e suas partes, muito decorrente do alto volume de exportação desses produtos pela Zona Franca de Manaus. Assim como uma pauta exportadora muito concentrada nas exportações é maléfico, uma pauta de importação também o é, pois isto representa uma dinâmica muito fraca no consumo.

Melo (2007), ao analisar a concentração das exportações e importações da Região Nordeste do Brasil, no período de 2002 a 2005, verificou situação semelhante à apresentada aqui pela Região Norte. A autora explica que o ideal é a presença de uma concentração das exportações maior que das importações, pois isto leva a uma maior especialização da produção, bem como uma maior diversificação do consumo. Ressalta ainda que essa característica da concentração maior das importações frente às exportações é decorrente de regiões pouco dinâmicas no comércio internacional. 
Tabela 5 - Índice de concentração das Exportações e Importações da Região Norte de 2014-2015 (em \%)

\begin{tabular}{lcc}
\hline \multicolumn{1}{c}{ Referência } & $\mathbf{2 0 1 5}$ & $\mathbf{2 0 1 4}$ \\
\hline Concentração das exportações (ICX) & 49,41 & 56,18 \\
Concentrações das importações (ICM) & 58,56 & 62,10 \\
Setores que compõem 90\% do valor das exportações & 49,34 & 56,03 \\
Setores que compõem 90\% do valor das importações & 64,18 & 62,70 \\
Comércio intra-setorial (IS) & 58,70 & 65,59 \\
\hline
\end{tabular}

Fonte: Elaborado pelos autores a partir da SECEX/MDIC (BRASIL, 2016).

Os resultados dos setores que compõem $90 \%$ do valor tanto das exportações quanto das importações só corroboram com as constatações anteriormente verificadas, de uma alta concentração na pauta de ambas. A concentração das importações passa a representar mais de $64 \%$ quando considerado o conjunto dos $90 \%$ dos setores mais importantes em 2015, portanto, elevando-se $1,48 \%$ de 2014 a 2015.

Não diferente, tem-se o indicador de comércio intrassetorial em que se mostra a pauta de setores exportadores diretamente relacionada com o mesmo setor de importação, ou seja, produtos que a Região normalmente exporta também são importados, obviamente que muitos desses produtos são importados não pelo mesmo estado que exporta. Esse indicador apresentou uma redução nos últimos dois anos, mostrando que os termos de trocas entre os mesmos produtos têm diminuído como é o caso de produtos químicos e inorgânicos; compostos inorgânicos ou orgânicos; máquinas, aparelhos, materiais elétricos e suas partes; e reatores nucleares, caldeiras, máquinas, aparelhos e instrumentos mecânicos, e suas partes.

\section{CONSIDERAÇÕES FINAIS}

A inserção regional no contexto de comércio exterior nacional é uma temática de extrema relevância dentro da dinâmica das economias cada vez mais globalizadas. Nesse ínterim, esta pesquisa teve como objetivo analisar a inserção da Região Norte do Brasil no comércio exterior brasileiro nos últimos 10 anos (2006-2015).

Para tanto, foi trabalhada a caracterização da Região Norte do Brasil e sua dinâmica no cenário internacional. O cálculo do indicador de concentração das exportações (ICX) e das importações (ICM), bem como o índice de comércio intrassetorial permitiu entender o comportamento da inserção do Norte brasileiro no contexto de comércio exterior brasileiro. Toda a análise teve como base de dados o Ministério da Indústria, Comércio Exterior e Serviços.

A Região Norte representou 6,91\% do total das exportações brasileiras em 2015 e 13,08\% no saldo geral da balança comercial, seguindo as tendências nacionais quanto a sua balança comercial e a participação dos setores por fator agregado. Chamou atenção um nível de mais de $90 \%$ de importação de produtos industrializados. Esse resultado atrela-se à presença da Zona Franca de Manaus, haja vista ser grande importador de produtos manufaturados com a garantia de condições fiscais especiais, o que prova o déficit na balança comercial do Estado do Amazonas, que, inclusive, é o único Estado a apresentar saldo negativo ao longo de 2006 a 2015.

Observada a participação dos setores de produtos na pauta de exportação ficou claro que minérios, escórias e cinzas são aqueles que se destacam, pois concentram mais de $45 \%$ de toda a pauta da região. Além dessa alta participação do setor de minérios, o Estado do Pará detém mais 
de $99 \%$ de toda a produção desse setor na região. Isto representa um dado preocupante, haja vista que essa dependência provoca uma instabilidade e desequilíbrio regional, principalmente no caso de uma queda da comercialização de produtos desse setor com o resto do mundo.

Por fim, os índices de concentração de exportação (ICX), de concentração de importação (ICM) e de comércio intrassetorial (IS) só confirmaram as evidências até então apresentadas, inclusive, com um ICM maior que o ICX, mostrando o pouco dinamismo regional frente ao comércio exterior. Esses resultados reforçam a vulnerabilidade que a Região Norte possui dentro do contexto nacional, mesmo com uma Zona Franca e áreas de livre comércio, como é o caso dos Estados do Acre, Amazonas, Rondônia, Roraima e cidades de Macapá e Santana no Amapá.

Assim sendo, sugere-se a adoção de políticas públicas de comércio exterior na região que valorizem a produção interna aos estados, como a criação e fortalecimento das Zonas de Processamentos de Exportação (ZPE). A diversificação na pauta exportadora, através da adoção de novos acordos de comércio exterior, também é uma necessidade premente, principalmente com os países que fazem fronteira com os estados da região, como é o caso de Peru, Bolívia, Colômbia e Venezuela, isto é, deixar de ter o "olhar" somente para o Atlântico e virar-se mais ao Pacífico.

Não obstante, esclarece-se que a pesquisa trata de um estudo primário das relações comerciais do norte brasileiro com o resto do mundo e que se trata de uma pesquisa exploratória. Assim sendo, indica-se para pesquisas futuras na área a abordagem sobre as principais políticas públicas adotadas na região para o comércio exterior, quais seus efeitos e se tiveram como foco a diversificação e expansão da pauta exportadora.

\section{REFERÊNCIAS}

ALVARENGA, G. L. Análise econométrica da competitividade entre Brasil e Colômbia no mercado de café arábica. 2015. 90 f. Dissertação (Mestrado em Administração) - Universidade Federal de Lavras, MG, 2015. ASSOCIAÇÃO DE COMÉRCIO EXTERIOR DO BRASIL (AEB). Radiografia do comércio exterior brasileiro: passado, presente e futuro. Documento online, Rio de Janeiro, 2012. Disponível em: <http://www.aeb. org.br/userfiles/file/AEB\%20-\%20Radiografia\%20Com\%C3\%A9rcio\%20Exterior\%20Brasil.pdf>. Acesso em: 22 jul. 2016.

BAUMANN, R. Brazilian external sector so far in the $21^{\text {st }}$ century. Revista Brasileira de Politica Internacional. Brasília, v. 53, n. especial, p. 33-53, 2010. Disponível em: <http://www.scielo.br/pdf/rbpi/v53nspe/ v53nspea03.pdf>. Acesso em: 8 jul. 2016.

BRASIL. Ministério da Indústria, Comércio Exterior e Serviços. Estatísticas de Comércio Exterior. Brasília, DF, 2016. Disponível em: <http://www.mdic.gov.br/comercio-exterior/estatisticas-de-comercio-exterior>. Acesso em: 10 jul. 2016.

. Decreto-Lei n. 288, de 28 de fevereiro de 1967. Brasília, DF, 1967. Disponível em: <http://www. planalto.gov.br/ccivil_03/decreto-lei/Del0288.htm>. Acesso em: 22 jul. 2016.

COUTINHO, E. S. et al. De Smith a Porter: um ensaio sobre as teorias de Comércio Exterior. Revista de Gestão USP, São Paulo, v. 12, n. 4, p. 101-113, out./dez. 2005.

GORDON, J. L.; GRAMKOW, C. L. As características estruturais da inserção externa brasileira e suas principais implicações - 2000/2010. Cadernos do Desenvolvimento, Rio de Janeiro, v. 6, n. 9, p. 93-118, jul./dez. 2011.

GREENAWAY, D.; MILNER, C. What Have We Learned from a Generation's Research on Intra-Industry Trade? Research Paper Series, University of Nottingham, 2003. Disponível em: <http://www.nottingham. ac.uk/gep/documents/papers/2003/03-44.pdf>. Acesso em: 21 jul. 2016. 
KRUGMAN, P. R.; OBSTEFELD, M. Economia internacional: teoria e política. 6. ed. São Paulo: Pearson, 2005. LACERDA, A. C. A inserção internacional brasileira. In: BIELSCHOWSKY, R. et al. O desenvolvimento econômico brasileiro e a Caixa: palestras. Rio de Janeiro: Centro Internacional Celso Furtado para o Desenvolvimento/ Caixa Econômica Federal, 2011. p. 43-48. Disponível em: <http://www.centrocelsofurtado.org.br/arquivos/ image/201109261240050.LivroCAIXA_C_0.pdf>. Acesso em: 21 jul. 2016.

. Investimentos diretos estrangeiros e políticas de desenvolvimento. Revista Administração em Diálogo, São Paulo, n. 05, p. 11-18, 2003.

MEDEIROS, C. A.; SERRANO, F. Inserção externa, exportações e crescimento no Brasil. In: FIORI, José Luís; MEDEIROS, Carlos (Org.). Polarização mundial e crescimento. 1. ed. Petrópolis, RJ: Vozes, 2001. v. 1, p. 105-135.

MELO, M. C. P de. Comércio exterior da Região Nordeste na esteira do "Efeito China". Revista Econômica do Nordeste, Fortaleza, CE, v. 44, n. 2, p. 453-474, abr./jun. 2013. Disponível em: <http://www.bnb.gov. br/projwebren/Exec/artigoRenPDF.aspx?cd_artigo_ren=1374>. Acesso em: 20 jun. 2016.

. Inserção internacional da Região Nordeste e a dinâmica do comércio exterior brasileiro nos anos recentes. Revista Econômica do Nordeste, Fortaleza, CE, v. 38, n. 4, p. 583-601, out./dez. 2007. Disponível em: <http://www.bnb.gov.br/projwebren/Exec/artigoRenPDF.aspx?cd_artigo_ren=1063>. Acesso em: 15 jun. 2016.

PORTER, M. E. A vantagem competitiva das nações. Rio de Janeiro: Campus, 1989.

RICARDO, D. Princípios da economia política e tributação. São Paulo: Nova Cultural, 1996. (Coleção Os Economistas).

SARQUIS, S. J. B. Comércio internacional e crescimento econômico no Brasil. Brasília: Fundação Alexandre Gusmão, 2011. 248 p.

SCHNEIDER, M. B.; ARAÚJO, R. H. Balança comercial agrícola paranaense: conjuntura pós-crise financeira de 2008. Revista Orbis Latina, v. 4, n. 1, p. 185-201, jan./dez. 2014.

SILVA, J. L. M.; MONTALVÁN, D. B. V. Exportações do Rio Grande do Norte: estrutura, vantagens comparativas e comércio intra-indústrial. Revista de Estudos Regionais, Piracicaba, SP, v. 46, n. 02, p. 547-568, abr./jun. 2008. Disponível em: <http://www.scielo.br/pdf/resr/v46n2/v46n2a10.pdf>. Acesso em: 21 jul. 2015.

SILVA, D. B. L. O impacto da abertura comercial sobre a produtividade da indústria brasileira. 2004. $42 \mathrm{f}$. Dissertação (Mestrado em Finanças e Economia Empresarial) - Escola de Pós-Graduação em Economia, Fundação Getúlio Vargas, Rio de Janeiro, 2004.

SMITH, A. A riqueza das nações: investigação sobre a natureza e suas causas. São Paulo: Nova Cultural, 1996. (Coleção Os Economistas). Originalmente publicado em 1776.

SUPERINTENDÊNCIA DA ZONA FRANCA DE MANAUS (SUFRAMA). Zona Franca de Manaus: história. Manaus, AM, 2016. Disponível em: <http://www.suframa.gov.br/zfm_historia.cfm>. Acesso em: 22 jul. 2016.

VILLA VERDE, R. B. R.; ALAMINO, R. C. J.; FERNANDES, F. R. C. Os desafios da extração mineral na Região Norte em prol do desenvolvimento socioeconômico. In: FERNANDES, F. R. C.; ALAMINO, R. C. J.; ARAUJO, E. R. Recursos naturais e comunidade: impactos humanos, socioambientais e econômicos. Rio de Janeiro: CETEC/MCTI, 2014. p. 13-21. Disponível em: <http://mineralis.cetem.gov.br/bitstream/ handle/cetem/1729/Livro_Recursos_Minerais_E_Comunidade_FormatoA4_em14_outubro_2014. pdf?sequence=1>. Acesso em: 22 jul. 2016.

\section{Sobre os autores:}

Mário Sérgio Pedroza Lobão: Doutorando em Desenvolvimento Regional e Agronegócio pela Universidade Estadual do Oeste do Paraná (UNIOESTE), Economista e Mestre em Desenvolvimento Regional pela Universidade Federal do Acre (UFAC). Professor de Economia no Instituto Federal do Acre (IFAC). E-mail: mario.lobao@ifac.edu.br 
Alexandre de Souza Corrêa: Doutorando em Desenvolvimento Regional e Agronegócio, Mestre em Geografia, Bacharel em Economia e Professor da Universidade Federal da Grande Dourados (UFGD). E-mail: asc_alexandre@hotmail.com

Mirian Beatriz Schneider: Professora adjunta da Universidade Estadual do Oeste do Paraná (UNIOESTE/Campus de Toledo). Doutora em História Econômica pela Universidade de León, mestre em Desenvolvimento Econômico pela Universidade Federal do Paraná e graduada em Ciências Econômicas pela Universidade Estadual do Oeste do Paraná. E-mail: mirianbraun@ hotmail.com 
